\title{
TRAINING FOR RESEARCH IN COMMUNITY MENTAL HEALTH
}

\author{
LENIN A. BALER, Ph.D., S.D. in Hyg.*
}

Training institutions need to do a more adequate job in socializing students early and continuously for the role of community mental health researcher. While psychology is singled out to illustrate this thesis, all the disciplines that make up the community mental health team could profitably be examined from this standpoint. The university climate in which psychologists are reared is examined and nuclear shortcomings in respect to basic trust, feelings of competence, and sense of identity are dramatized.

Concerning research in the community mental health field, there would appear to be consensus on two points. First, the most urgent need is for basic and applied research on a wide scale. This assertion occurs in epidemic frequency in most official documents, conference reports, position papers, and symposia. It also typically appears in more muted form in the last paragraph of agency annual reports. Second, among the various specialties in mental health, psychology is expected, by virtue of its constitutionally defined self-image as both a science and a profession, to be ethically committed to doing research. To be sure, the relative ratio of research to practice is sensibly permitted to vary with the interest intensity and competence level of the individual psychologist, but university training programs have always operated on the assumption that the individual psychologist's direct and indirect contribution to research should be well above zero.

Now, if the community at large can confront the mental health professions with the challenge of enabling legislation and logistical support to launch a "bold, new approach" to the prevention and control of mental disorders, it would seem only fitting that psychologists accept the in-group challenge to train students so that they will be equipped with the requisite skills and motivation to make a contribution to community mental health research that will indeed be well above zero.

Manpower resources are such that students at all levels of training ought to be of some value in the research effort. It is certainly regrettable that the large number of talented psychology students who do not go beyond the Bachelor's degree are lost to the manpower pool as potential research assistants and technicians frankly because their present undergraduate education has just about zero transfer value for community research tasks. Present doctoral training, in particular in clinical psychology, automatically produces, at least in the opinion of several observers, negative transfer value. Finally, staff members involved in postdoctoral community mental health specialist programs sometimes feel that it is too late and that as in psychotherapy few patients can really be "cured" in spite of best efforts!

The thesis of this paper is that training institutions need to socialize students early and continuously for the role of community mental health researcher.

One cannot, in fairness, identify a problem without proferring at least a few speculations as to the required remedy. Perhaps the simplest way of doing this is to organize the discussion around three concepts universally used when psychologists talk about the socialization process: basic trust, feelings of competence, and sense of identity.

\section{Basic Trust}

It is painful to note that psychologists who as professionals seek so earnestly to promote mental health in others by arguing the case for basic trust as nuclear to maturity in any social role have often failed to secure this "highest good" for themselves

*Dr. Baler, a psychologist, is Associate Professor of Community Mental Health, University of Michigan School of Public Health, Ann Arbor, Michigan. This article is a revision of "The Psychologist as Community Mental Health Research Specialist," a paper read at the Annual Meeting of the American Psycho. logical Association, New York, 1966. 
within their own training institutions. The reference here, of course, is to the longendemic irrational and destructive clash between the so-called scientists and the practitioners within university psychology departments and between academic staff and community line workers. Probably few students, indeed, have failed to perceive this climate of distrust and consequently to suffer constraints upon their own full development as psychologists.

An articulate and thoroughly incisive analysis of this situation has recently been made by Chein (1966). He takes a close look at the problem as a social process, as the clash of two subcultures, and as a political conflict. One of the serious consequences of this basic distrust is the derogation of scholarship. In Chein's words, "blatant ignorance, stereotyping, and lack of comprehension become a sufficient basis for oracular pronouncements on the incompetence of the outermost out-group to make any significant contributions to psychology." Particularly disconcerting is that community mental health workers (whether in research or practice) currently constitute the most likely candidates for Chein's "outermost out-group" label.

The solution Chein proposes seems entirely reasonable. He says, "I am, thus, not pleading for a burial of differences. On the contrary, I am saying that we should open them up and bring them out from behind the fog of interpersonal and intergroup hostility. It is time for us to grow up and stop confusing our interpersonal and intergroup problems with the business of psychology." It needs only to be added that a similar solution is applicable to the divisiveness between psychologists and psychiatrists if they are to work really productively together in practice and research in the community mental health field.

If the present schism between the scientist and the practitioner continues unabated in the university, the university will remain a grossly inept socializing agent for training psychologists in community mental health. The academic scientist can produce much useful research even though he may escape into scientism. The clinical prac- titioner can contribute significantly to human welfare even though he may escape into clinicalism. In contrast, a line community mental health researcher cannot function with such a one-sided identity pattern; he must achieve an integrated identity as scientist-practitioner (Gelfand \& Kelly, 1960). This is so because there is no such thing as community research apart from community practice. As long as psychologists are reared in a climate of distrust that demands schizophrenic adjustments to the scientist and practitioner roles, competent community mental health researchers will remain in very short supply.

\section{Feelings of Competence}

One normally prefers to do what he feels competent to do. Psychologists as presently trained are all too frequently dramatically incompetent to undertake community research. Even senior psychologists enrolled in postdoctoral community mental health training programs often lack rudimentary practical knowledge of community organization, are totally inexperienced in operating in the real community in regard to sanction problems or collaboration with nonprofessionals, and find embryonic their mastery of relevant technical research skills, such as questionnaire construction, survey methodology, and the art of just plain naturalistic observation. This situation is rather appalling when one recalls that in the first lecture in introductory psychology the instructor is apt to write on the board the universally accepted formula "Behavior results from the interaction between the person and his environment." It is hard to understand how the study of the environment (in terms of the customary goals of description, prediction, and control) is subsequently so neglected conceptually in the curriculum and neglected experientially in field assignments. As pointed out earlier, adequate socialization for the role of community mental health research worker must begin early and occur continuously.

\section{Community Practicum}

Absolutely mandatory is the development of a series of graded community practicum 
experiences that begin as early as possible in undergraduate training in psychology. These can vary from simple homework exercises, tutorial supervision, clerkship, and extra assignments to summer apprenticeship and internship placement. What can be the objections to this? It will "water down" the intellectual quality of college work? Nonsense. It has every chance of doing just the opposite by enriching the student's awareness of the nature of reliable and valid data, the utility of theories and conceptual models for formulating hypotheses, and the operational complexity of research designs required to test such hypotheses. Another objection may be that the average undergraduate is not mature enough to carry out and to benefit from such assignments. Again, nonsense; look at what young people are able to do and learn as mental health volunteers, as Vista workers in the poverty program, as "big brothers and sisters" in delinquency control. The main requirement for success is that the community practicum be overtly and honestly valued by the faculty and integrated thoroughly into the formal classroom subject matter. Basic trust thus continues to be of overriding importance.

What are some specific examples of practicum experiences of potential value in the early socialization of psychologists as community mental health research workers? Space permits a sketchy listing of only five:

1. For a given community, obtain the U S. census data for 1950 and 1960. What demographic and socioeconomic changes have occurred? Discuss the implications in terms of the need for mental health services of different types.

2. Administer a questionnaire that taps attitudes toward mental illness of members of the local police force. Discuss the results with reference to the need for a mental health in-service training program for the police.

3. In collaboration with the staff of the local high school, compute the overall dropout rate over the past five years. See if the rate varies with some other variable, such as age or sex.

4. A certain health bill is coming up for legislative hearings. Attend these and observe what agencies present arguments pro and con. Follow up with individual interviews to ascertain agency goals and motivations behind the official position on the bill.

5. During the summer, volunteer to serve as an aide to a public health nurse. Accompany her on home visits. Keep a daily $\log$ and write a final report highlighting how her job involves mental health work directly and indirectly.

To summarize at this point, the contention here is that unless psychologists are socialized early in some fashion along the lines suggested above they will be unlikely to develop a serious interest in community mental health research during doctoral training or later in their career.

\section{Formal Classroom Instruction}

The acquisition of feelings of competence as a community research worker requires not only the community practicum experience just discussed but also is dependent upon adequate classroom instruction in relevant research logic and methodology. That something is very much amiss here has been recognized by many. Recently Marvin Dunnette (1966) has cleverly pinpointed the details of the problem. Taking his cue from Berne (1964), Dunnette examines the games that psychologists play in the name of science but which lead "down the primrose path to nonscience" and to nonsense. One instance of Dunnette's slashing insight can be seen in his definition of folderol as "those practices characterized by ... . wasteful fiddle-faddle-including tendencies to be fixated on theories, methods, and points of view, conducting 'little' studies with great precision . . . asking unimportant or irrelevant questions ... coining new names for old concepts. ..."

Learning how to "play games" has its own reward, to be sure. The reward clearly is not, however, feelings of competence in skills relevant to community mental health line research. A solution is exceedingly difficult to come by, because the acquired love of gamesmanship perpetuates itself as each new generation of students passes through the university. A moral injunction "Let's 
stop playing games!" merely raises the suspicion that some fascinating new game is about to be played.

A few psychologists have managed to reject the "establishment" and happily have been socialized in the real world of social commitment and social action research. Part of the solution to the problem under discussion is somehow to get these individuals to accept appointments on the faculties of our academic institutions. Another part of the solution lies in getting some of the more promising university scientists out of the ivory tower to function, not as mere alienated consultants, but as line researchers on the community team. Maybe then students can learn the basic research skills they really need: the ability to accept without paralyzing anxiety the fact that nonexperimental data is unwieldy, the ability to see a correlation based on naturalistic observation, not as an object of disparagement, but as a challenge to explore further whether the relationship is direct, indirect, or simply spurious, the ability to undertake applied research without feeling that one is committing an unforgivable sin.

\section{Sense of Identity}

The task of completing the socialization of the psychologist for the role of community mental health research worker falls necessarily to the community mental health field agency itself. It is here "on the firing line" that the sense of identity must be firmed up and spelled out. It is here where the action is that community research problems can most realistically be formulated. It is here where the newcomer must learn to get along with the other members of the multidisciplinary mental health team. It is here in the neighborhood around the agency that the community laboratory exists as the proper source of data and as the sounding board for action research. It is here, in short, where the acid test of selfworth as a community mental health research worker is given and scored and where the report card is issued.

The novice researcher must adjust to many problems, and he needs all the sense of trust his earlier training at the university has built into his role repertoire. He discovers quickly that he is not the central actor in the agency drama, that his colleagues are busy with incredibly heavy dayto-day workloads of service, that his administrators are preoccupied politically with winning program acceptance, that the community purse-holders are apt to regard research out of hand as mere frills, and that, on the surface at least, everyone accepts the worth of present services as face-valid and not requiring evaluative research.

Adaptation to this situation, interestingly enough, requires that the researcher use the practitioner skills acquired from earlier community practicum experiences to demonstrate that he feels competent to function as a researcher in such a way as to be of value to the agency and to the community. As Brooks (1965) states, the researcher can provide sensible ideas for experimenting with modifications in agency practice, collect and analyze demographic and other types of data necessary for agency planning, and assist in the planning process itself by helping the staff follow the steps in standard decision-making models. This type of cooperative behavior on the researcher's part is likely to lead automatically to agency sanction and encouragement to design and implement the basic research and program evaluative research that he is committed to as nuclear to his self-image. By way of contrast, if the researcher had come to the field agency without previously achieving a sense of trust and feelings of competence, he would almost certainly fail in turn to achieve an acceptable sense of identity.

\section{REFERENCES}

Berne, E. Games people play. New York: Grove Press, 1964.

Brooks, M. P. The community action program as a setting for applied research. J. soc. Issues, 1965, 21, 29-40.

Chein, I. Some sources of divisiveness among psychologists. Amer. Psychologist, 1966, 21, 333-342.

DunnetTe, M. D. Fads, fashions, and folderol in psychology. Amer. Psychologist, 1966, 21, 343-352.

Gelfand, S., \& Kelly, J. G. The psychologist in community mental health: scientist and professional. Amer. Psychologist, 1960, 15, 223-226. 